\title{
E-Learning and Its Impact on Rural Areas
}

\author{
Rimmi Anand \\ Assistant Professor, Department of Computer Applications, BIT College, Meerut, U.P., India. \\ sethi_rimmi@hotmail.com \\ Sharad Saxena \\ Assistant Professor, Department of Computer Applications, BIT College, Meerut, U.P., India. \\ sharadzoom@gmail.com \\ Shilpi Saxena \\ Lecturer, English Department, The Great Mind Day-Boarding College, Meerut, U.P., India.
}

\begin{abstract}
E-Learning is referred to as teaching and learning by using electronic media. This methodology supports the use of networking and communications technology in teaching and learning. E-Learning is generally meant for remote learning or distance learning, but can also be used in face-to-face mode. In this paper we have made study about the awareness and impact of E-Learning in selected rural areas in India, the providers and learners ratio and an analysis on the collected data has been made to find the advantages of E-Learning resources and their affect on social and mental development of the individuals belonging to rural areas.
\end{abstract}

Index Terms - E-Learning, media, rural-area, E-Learner

\section{Introduction}

E-Learning applications [1] and processes include computer-based, web-based, technology based learning and virtual education opportunities. Content delivery is with the help of Internet, intranet, extranet, audio or video tape, satellite TV, and CD-ROM and it includes media in the form of text, image, animation, streaming video and audio. It allows us to learn at our own way i.e. on our own time with a flexible, interactive and engaging online experience. In this process, educational activities can be accomplished by using networking and communications technology in online or offline, synchronous as well as asynchronous, networked or standalone teaching and learning. As popularity of Internet is growing day by day, E-Learning is also in growing interest. People have started using Internet for accessing information via Internet. The corporate sector which was providing distance education has also started using online learning as an added activity in their distance education because E-Learning is a way of improving the accessibility of the study material, moreover, the cost of accessing information online is decreasing by the advancement in the field of information and communication technology. Students and teachers are increasingly using accessing information online to support their learning and teaching. Now a days, the trend is of "blended learning" [2], that is learning is a combination of traditional learning as well as E-Learning. Today single teaching learning method is not effective. As traditional method has an advantage of how to teach or learn though E-Learning provides us the latest methods and statistics. Following are the features identified of E-Learning:

Learning is centered around the interests of the learner...

Learning is immersive-

learning by doing - and takes place not in a school but in an appropriate environment[3]

Therefore, "blended learning" provides us an interest and an appropriate environment to teaching learning process.

The main attribute of E-Learning is the flexibility of accessing information and resources. It refers to the access the use of information and resources at any time, place or pace according to one's convenience. Learner is not bound with the constraints of attending the lectures on fixed time or fixed location which may be far off from the residence. Another attribute is access of multimedia based resources; it means that different type of media like text, audio, video, animation, graphics, picture is supported by the network and communication technology, which makes possible the accessing of information by not only text or pictures but it also supports animations, videos, presentations, audio etc. which makes learning more interesting and effective. Moreover the information and communication technology provides us an opportunity to capture, store, and distribute information in the form of text, pictures and illustrations which includes multimedia-based simulations of simple and complex processes which are cheaply accessible.

The paper has been organized as: In section II we have performed literature survey. In section III data collection survey related to providers and content delivery method is described. Section IV provides impact of E-Learning in rural areas. E-Learning consequences in rural areas as results are discussed in section V. Finally section VI concludes the paper.

\section{Related Work}

Shiva Kanaujia et al. [4], discussed about the benefits of E-Learning and also suggested that E-education is not a new concept in India but has grown the importance with 
the growth of Internet. He also discussed the advantages of E-Learning mainly, the best information can be accessed from the place where it was originally created. The students can access the information across the world from their homes' only, which was a main constraint for those who cannot afford the opportunities due to the lack of financial aids or assistance. The impact and new challenges of E-Learning for the students and instructors are described by authors in [5]. He summarised that in online or distance E-Learning course, E-Learning presents a host of new support requirements, and institutions must provide the appropriate resources to address them.

Alyne Rothberg et. al. [6] has suggested organizational strategies for accessing E-Learning opportunities with having the availability of the broadband connection. They also discussed the Government policies/assistance in expanding broadband. Rural areas and residents face a number of issues when it comes to access to and adoption of broadband. The issues include availability, cost, and lack of technical skill and knowledge. The largest discrepancy in the reasons between rural and urban residents not having home internet is lack of access. He further recommended that access to broadband and online learning is a key element to prepare students and employees for the future. A strong correlation exists between broadband access and educational attainment, employment opportunities, and individual and community-wide economic viability.

Nilay M.Yajnik [7] had discussed about the Next Generation Internet, in which usage of the Internet is growing tremendously but restricting the applications like Virtual Reality to be made available for distance learning purpose without higher bandwidth. Next Generation Internet is the area of Digital Libraries which requires improved quality of services such as continuous digital video and audio. Author also discusses that Natural Language Interface, is a way by which humans can communicate with the machine in a language that is natural to them. It is in nascent stage today but has tremendous potential for rural areas. Rural based NGO's which are working for rural development could build such training applications directly without needing to wait for the IT industry to develop applications for them.

Dr. T. Rama Devi [8] presented initiation of National Institute of Rural Development (NIRD) using ICT tools for the training of persons involved in rural development programs of central and state governments. Success of ELearning will only come with clear and well-defined instructional objectives, through preparation of content and an infrastructure, which offer support for both participation and instructions. The organizations like NIRD may give a new paradigm for their training activities. NIRD is conducting about 180 training programmes in a calendar year. If they adopt E-Learning technologies in their training programmes it would be cost-effective.
Deepshikha Aggarwal [9], suggested that use of ELearning in vocational and informal training is very effective in a developing country like India where majority of population is illiterate and residing in rural areas. The regions where university infrastructure is not available people can access information and educate themselves via Web which is a very cheap solution and moreover will raise the level of education, literacy and economic development. Author summarised that the Indian market is in initial stage, but it will continue to acquire E-Learning teaching methodology in order to meet its educational need and enhancing business opportunities.

\section{E-Learning Providers’ Survey}

\section{A. The Sample Collection}

For the purpose of sample collection for E-Learning providers we have considered Uttar Pradesh (UP), a large state in India having both developed and undeveloped cities. The major cities considered for data collection is listed in Table I. The mean number of ELearning providers who validly responded to the survey is approximately12 per city, and the median is 10 , ranging from 04 (DA) to 21 (MU). In the smaller cities (BJ, BT, KH, DA) the survey covered the majority of the existing E-Learning providers, while in bigger cities (MT, GZ, HP, MZ, RO, MU) a more modest proportion of providers responded. The surveyed providers identified include public bodies, private companies and NGOs. Overall, the private sector predominates (76\%), but this differs from city to city. The percentage of providers is shown in Fig.1.

TABLE I: E-LEARNING PROVIDERS

\begin{tabular}{|l|c|c|}
\hline \multicolumn{1}{|c|}{ City Name } & Abbreviation & $\begin{array}{c}\text { Providers' } \\
\text { Count }\end{array}$ \\
\hline Meerut & MT & 15 \\
\hline Ghaziabad & GZ & 18 \\
\hline Bijnor & BJ & 09 \\
\hline Bagpat & BT & 06 \\
\hline Hapur & HP & 12 \\
\hline Muzaffarnagar & MZ & 20 \\
\hline Roorkee & RO & 16 \\
\hline Khautali & KH & 05 \\
\hline Daurala & DA & 04 \\
\hline Muradnagar & MU & 21 \\
\hline
\end{tabular}




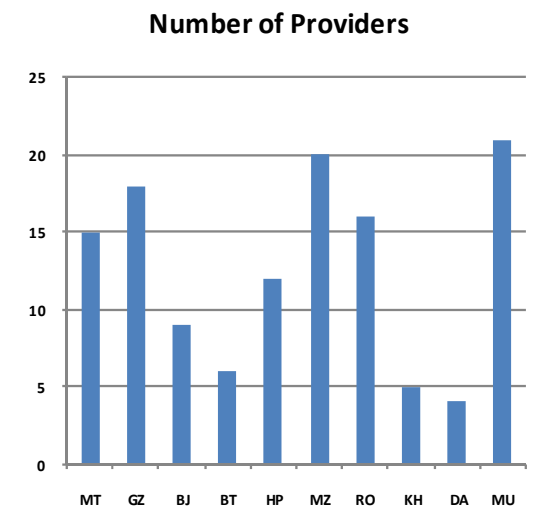

Figure 1. E-Learning providers: survey samples per city

\section{B. Providers' Profile}

Most of the E-Learning providers (68\%) are young organisations, with a presence of less than five years in the market, while almost one out of four providers has started their activity recently, not even counting a year of operation. In terms of size of providers, as indicated by the number of teachers employed, the sample includes micro, small, medium and large organisations, half of which employ less than 10 teachers and only one in four employ over 25 teachers. Almost three quarters of all providers employ 8 or less E-Learning teachers, and $86 \%$ employ 12 or less. The number of E-Learning students provides also an indication of the size of $\mathrm{E}$ Learning activity of providers: e-students range up to 700 , with a mean value of 520 and median of $120 \%$ of all providers have 120 or less students. The proportion of E-Learning teachers within the overall teaching staff provides an indication of the strength of the E-Learning activities in the organisation. This, coupled with the proportion of the E-Learning packages offered within the overall education output of the organisation underpins the specialisation of the provider in ELearning. The findings suggest that a relatively small proportion of the surveyed organisations are specialised E-Learning providers, delivering over $80 \%$ of their output wholly or partly through E-Learning. Specialised providers tend to be private organizations or NGOs that teaches large numbers of students with large student per teacher ratio.

\section{E-Learning Content and Delivery}

Regarding content of E-Learning (see Fig. 2), use of IT, Language and Technical subjects are the two most popular subjects, offered by 58\% of providers across cities, while the less popular subjects are those of the primary sector offered by less that $12 \%$ of providers, and as expected, these providers are amongst those with a stated orientation towards rural areas. Business management and services are also popular enough amongst providers, offered by $22-30 \%$ of the total sample. Overall, all types of subjects are covered in all cities, offering a good measure of choice to progressive learners.

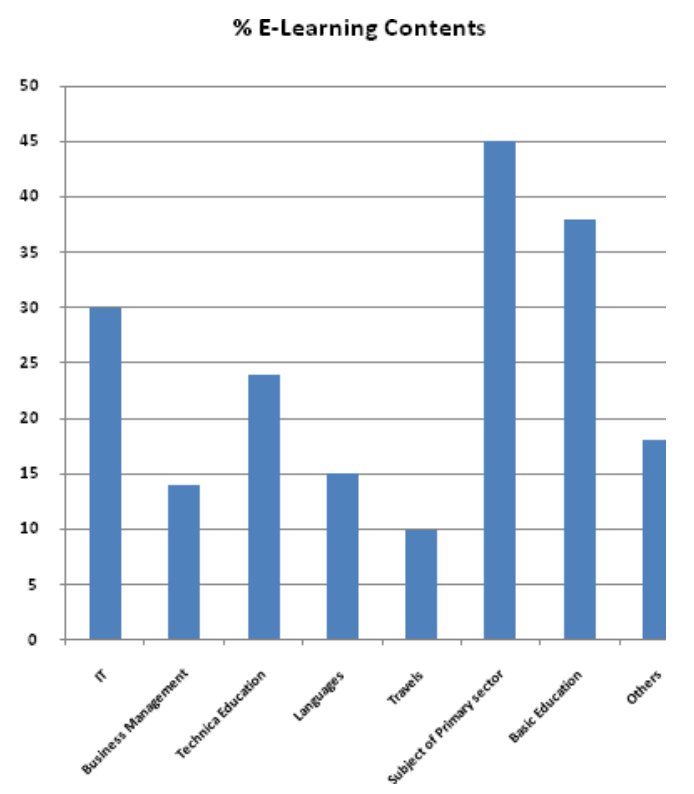

Figure 2. Subjects offered by E-Learning providers

The most popular delivery method is the E-Learning platform (88\% of providers) followed by websites, DVDs, CDs and Video. Mobile phones, i-phones and tablets are used only by a very small minority of providers (5\%). The learning tools used also show a preference for more conventional instruments, with very high proportions of providers using text reading and power-point presentations, followed by animated content, videos and email attachments. Game based learning and role based learning are used only by around one in four providers or less.

\section{Impact of E-Learning in Rural Areas as Identified}

Provider of E-Learning offers special packages of ELearning to rural inhabitants. They have designed their products for everybody, irrespective of their place of residence, rural or urban. The proportion of surveyed providers that target rural areas, providing specially prepared E-Learning packages for them, is just over $42 \%$ of the total sample and varies substantially from city to city. Those providers that offer special packages for rural areas (see Fig. 3 and Table II) are not very much different in their structural characteristics from other E-Learning providers. They recruit their own clients amongst micro and small enterprises to a much larger extent than other providers. 
TABLE II: \% OF PROVIDERS TARGETED TO RURAL AREAS

\begin{tabular}{|c|c|c|c|c|c|c|c|c|c|c|}
\hline 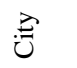 & $\sum$ & N & $\bar{D}$ & 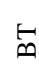 & 言 & $\sum$ & $\stackrel{\vartheta}{\simeq}$ & $\underline{I}$ & 㟔 & 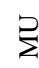 \\
\hline م゚ & 42 & 43 & 38 & 32 & 25 & 31 & 33 & 14 & 12 & 10 \\
\hline
\end{tabular}

Providers Targeting Rural Areas

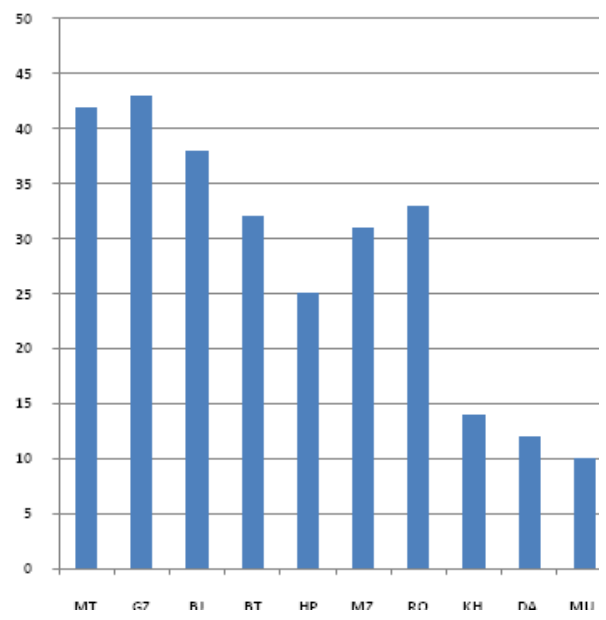

Figure 3. Providers targeting Rural Areas

\section{A. Problems and success factors}

The problems associated with delivering E-Learning in rural areas, which most providers agree about is lack of suitable infrastructure for fast Internet connectivity. In BT, DA, KH and HP this statement was endorsed by over $80 \%$ of providers, while in other cities it was $20 \%$. IT illiteracy was also mentioned as a problem by half the providers overall, taking its maximum value in DA and $\mathrm{KH}$ (over 68\%) while limited financial capacity of rural residents and lack of support staff in rural areas was mentioned by one in four providers (see Table III and Fig. 4).

TABLE III: \% PROBLEM ASSOCIATED TO E-LEARNING IN RURAL AREAS

\begin{tabular}{|c|c|c|c|c|c|c|c|c|c|}
\hline 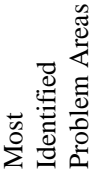 & $\begin{array}{l}\frac{n}{\mathscr{U}} \\
\stackrel{5}{0}\end{array}$ & 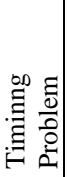 & 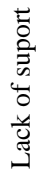 & 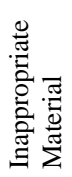 & 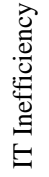 & 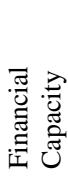 & 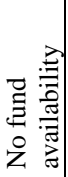 & 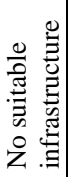 & 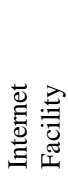 \\
\hline 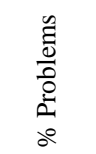 & 11 & 12 & 14 & 16 & 17 & 20 & 22 & 26 & 27 \\
\hline
\end{tabular}

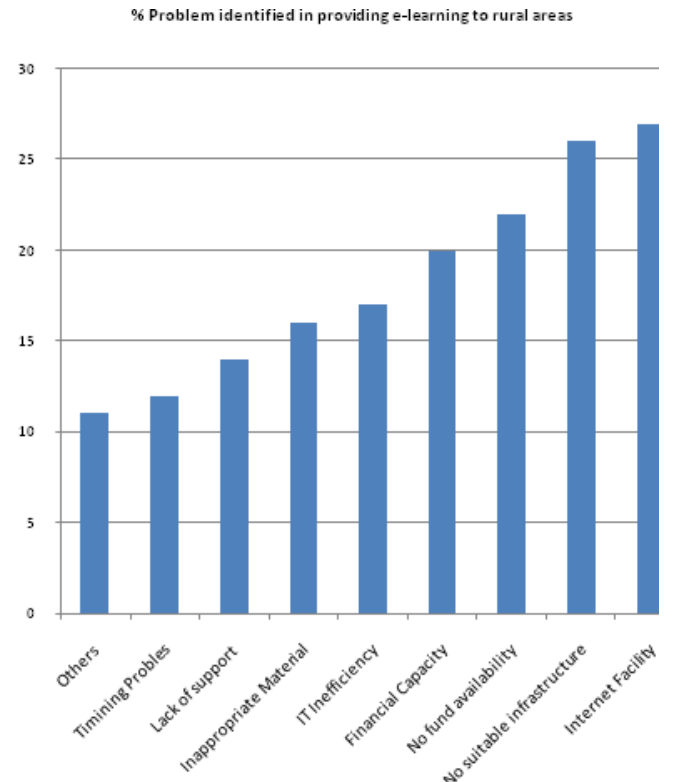

Figure 4. Problems Identified in Rural Areas

TABLE IV: TYPICAL FACTOR FOR E-LEARNING

\begin{tabular}{|c|c|c|c|c|c|c|c|c|}
\hline \multicolumn{9}{|c|}{ FACILITATING } \\
\hline Heads & 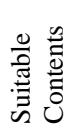 & 岕 & 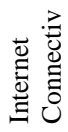 & 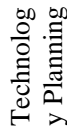 & 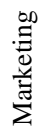 & 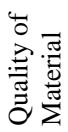 & 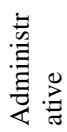 & 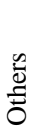 \\
\hline $\begin{array}{l}\% \\
\text { Efforts }\end{array}$ & 35 & 32 & 28 & 26 & 25 & 30 & 16 & 15 \\
\hline
\end{tabular}

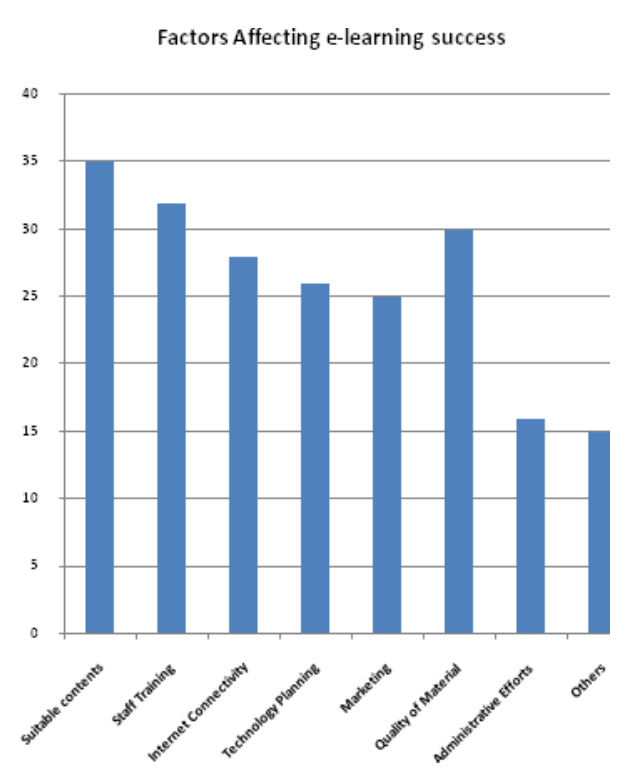

Figure 5. E-Learning success factors

Critical factors for successful provision (see Table IV and Fig. 5) of E-Learning were endorsed by the surveyed providers from a range including fast Internet, development of learning content, marketing, keeping ahead with new technologies and training of staff. The 
most "critical" factor is the development of suitable learning content that suits the needs of learners. Also, high importance is placed on the training of staff that design and deliver E-Learning; and on planning ahead with new technologies, so that the means of E-Learning delivery do not become obsolete. Factors for success on the learner's side were pointed out by the providers to be mostly their willingness to learn and self-discipline.

\section{Result And Discussions}

E-Learners are the entities which are recruited by the providers to take part in the survey. The learners are divided into groups to provide information on their socio-economic characteristics which made it possible to compare them as well as portray the structure of each sample. The results obtained from groups are compared in terms of gender, age and education. The result is analysed in terms of satisfaction from E-Learning, current use of material and expectation from the ELearning.

Satisfaction from E-Learning: Considering the benefits experienced by learners, one in five E-Learners stated that they learned all they needed, while one in two reported that they learned enough. Overall, over $70 \%$ of the E-Learners stated that their needs were satisfied more or less. This however reflects partly the extent to which they use what they learned: less than $46 \%$ use it a lot, and less than $35 \%$ use it a little. The satisfaction graph is shown in Fig. 6.

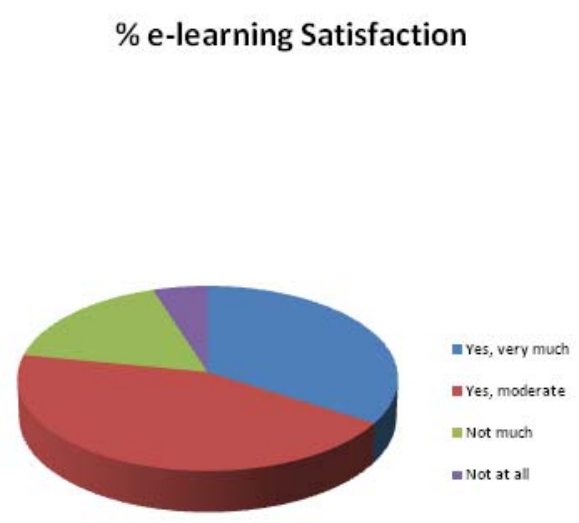

Figure 6. Satisfaction from E-Learning

Current use of material: The benefits reported by ELearner groups reflect that E-Learners are rather pessimistic regarding the benefits from the course they attended: $46 \%$ do not expect any benefits, $20 \%$ of the learner group members reported absence of real benefits. A personal interest accounts for the main benefit reported by the E-Learners (44\%)(see Fig. 7). A relatively important benefit is also to continue (secure) present job, which is reported by one in four E-Learners.

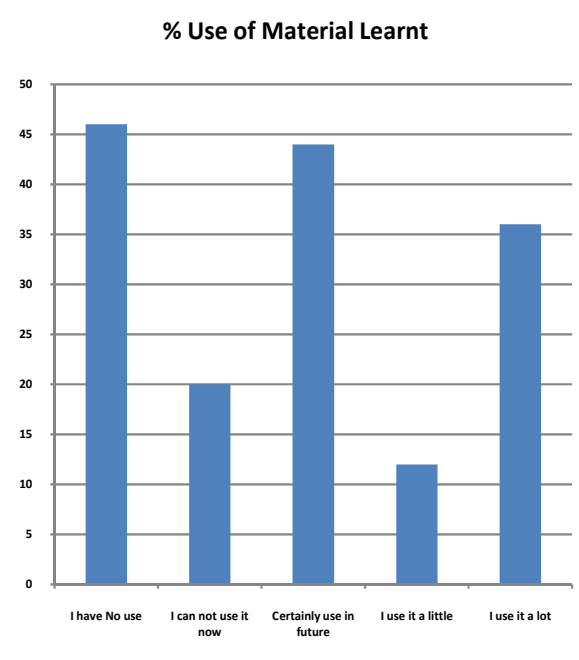

Figure 7. Use of E-Learning material

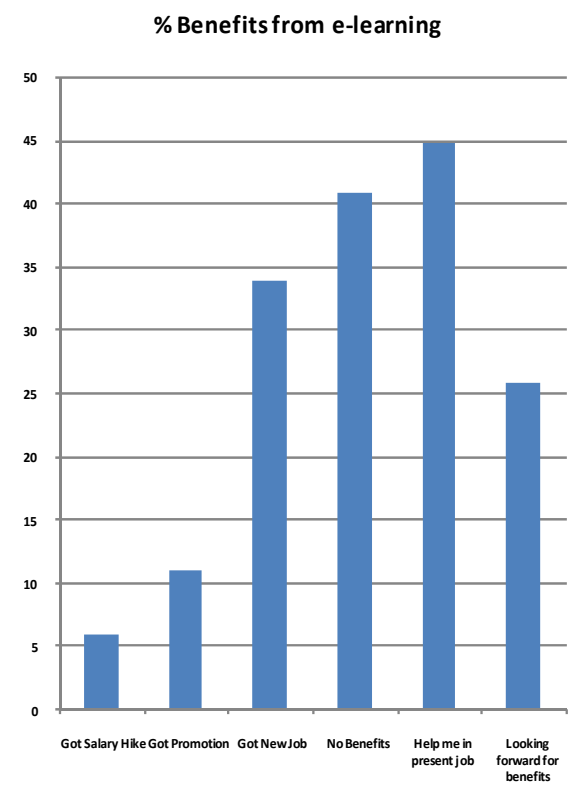

Figure 8. E-Learning Benefits 


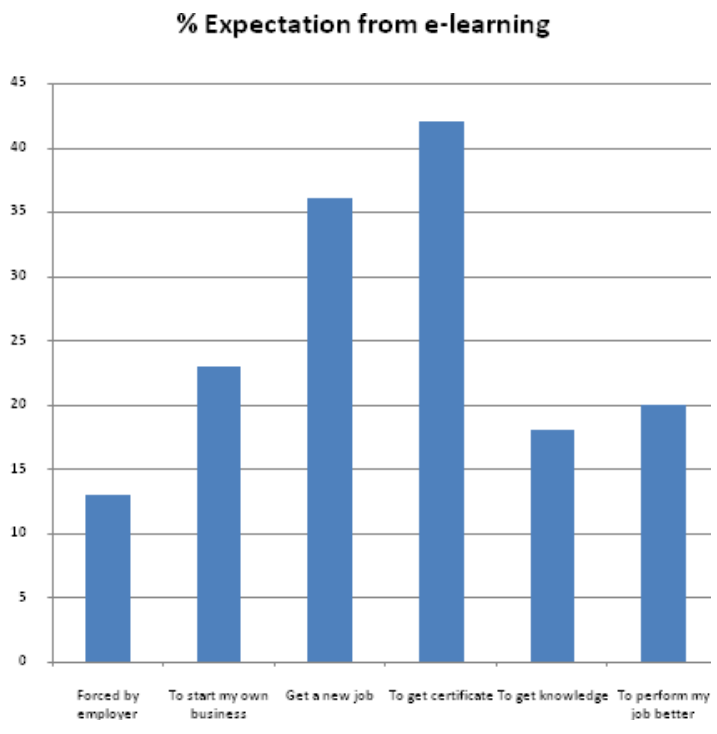

gure 9. E-Learning Expectation

Overall, it is observed that conventional training has more immediate benefits to trainees in all the examined categories, while E-Learning is considered by a large number of E-Learners as an investment for the future. Also, the fact that a large proportion of respondents, who have reported the development of a personal interest, as a real benefits are very encouraging for future. It is also interesting to compare the benefits achieved to the initial expectations of learners, before they started the training course, as reported by them. As shown in the Fig. 8 and Fig. 9, job-related expectations were much higher than the benefits achieved; while the cultivation of a personal interest featured a little higher in benefits as it did in expectations.

Expectations from learning: However, despite the gap between the expectations and the achieved job-related benefits, an amazing 95\% of E-Learners declared that they would be willing to participate again in E-Learning in the future, implying that the experience of being $\mathrm{E}$ Learners was a very positive one. The variation between the different cities is minimal in this respect.

\section{Conclusion}

E-Learning is found to be highly emerging knowledge tool today. It has wide scope in developed as well as in developing countries. The areas which are undeveloped and not so educated get attraction of ELearning. E-Learning provides a method of delivering knowledgeable contents through CD, DVD, multimedia and other tools. The main constraint identified in this process is availability of proper bandwidth, willingness of E-Learners and some sort of skill set to deliver the material to learners. Overall, $48 \%$ providers found ELearning is beneficial to rural gentry for knowledge, better job opportunities, and promotions and to learn new developing technologies in the market. Specially focusing towards rural areas it helps in developing people's social and mental ability. Although some negative consequences are also observed in flourishing E-Learning in rural areas because of lack of awareness, unwillingness, illiteracy and lack of proper infrastructure, yet it has a broad scope in near future and we believe that it will definitely help poor gentry to fill the gap between educated developed cities and rural undeveloped areas.

\section{References}

[1] Chen Xin, "E-Learning Applications and Challenges”, IEEExplore, pp 580-583, 2009.

[2] Luciana Carabaneanu, Romica Trandafir, Ion Mierlus Mazilu, “TRENDS IN E-LEARNING”, http://www.codewitz.net/papers/MMT_106111_Tren ds_in_E-Learning.pdf.

[3] Tony Bates, "Understanding Web 2.0 and its Implications for E-Learning”, Information science reference, chapter 2, http://www.igiglobal.com/chapter/web-based-learning/45015.

[4] Shiva Kanaujia, N R Satyanarayana, "E-Education in India: Pace of Learning on a Hi-Tech Path”, 2nd International CALIBER, New Delhi, 11-13 February, 2004.

[5] EDUCASE Chapter 6, "Impact and Challenges of ELearning”, Supporting E-Learning in Higher Education, Center for Applied Research, vol.3, 2003.

[6] Alyne Rothberg, Janet Bailey, Karen Ballard, "ELEARNING IN RURAL ENVIRONMENTS”, http://www.swdsi.org/swdsi2012/proceedings_2012/ papers/.../PA150.pdf

[7] Nilay M.Yajnik, “E-Learning Technologies for Rural India”, http://www. cdac.ernet.in/html/pdf/ Session2.3.pdf

[8] Dr. T. Rama Devi, “E-Learning Tools and Technologies for Rural Development Community with special reference to training: Experiences of National Institute of Rural Development”, DRTC ICT Conference on Digital Learning Environment, 11th -13th January, DRTC, Bangalore, 2006.

[9] Deepshikha Aggarwal, "Role of E-Learning in A Developing Country Like India”, 3rd National Conference; Computing For Nation Development, February 26 - 27, 2009 Bharati Vidyapeeth's Institute of Computer Applications and Management, New Delhi, INDIACom-2009.

Rimmi Anand, did MCA in 2002. She is pursuing research work in the area of teaching-learning process among different areas of education. She had attended many workshops on Good Teaching aids. She had attended 4 national level conferences at different colleges. Presently she is working as Assistant Professor in the department of Computer Application at Bharat Institute of Technology, Meerut, UP, India.

Sharad Saxena, did M. Tech. (Computer Science and Engineering) in 2009 from Shobhit University, Meerut, UP, India. He is pursuing Ph.D. in Computer Science and Engineering from Uttarakhand Technical University, 
Dehradun, UK, India. He has published 8 International Papers in the area of Ad-hoc and sensor networks in journal of repute. He has guided $2 \mathrm{M}$. Tech. Students in there dissertation work. His research interest includes Wireless Sensor Networks, Distributed Systems, and Mobile Computing, with a focus on Mobile Ad-Hoc Networks. Presently he is working as Assistant Professor in the department of Computer Application at Bharat Institute of Technology, Meerut, UP, India.

Shilpi Saxena, did M. Ed. (Education) in 2010 from Chaudhary Charan Singh University, Meerut, UP, India and B.Ed. (English Literature) from M.J.P. Rohillkhand University, Bareilly, UP, India. Recetly she is involved in the research area of E-Learning, computer literacy and there scope in undeveloped areas. She has attended and participated in 3 national conferences in the same domain in different colleges. Presently she is working as Lecturer in English Department at The Great Mind Day Boarding College, Meerut, UP, India. 